\title{
Metformin acts to suppress $\beta$-hydroxybutyric acid- mediated inflammatory responses through activation of AMPK signalling in bovine hepatocytes
}

Tianle Xu ( $\boldsymbol{\nabla}$ tl-xu@outlook.com )

Yangzhou University https://orcid.org/0000-0002-8479-3372

\section{Xubin Lu}

Yangzhou University

Abdelaziz Adam Idriss Arbab

Yangzhou University

\section{Xinyue Wu}

Yangzhou University

\section{Yongjiang Mao}

Yangzhou University

\section{Zhangping Yang}

Yangzhou University https://orcid.org/0000-0002-5479-8447

\section{Research Article}

Keywords: Bovine hepatocytes, $\beta$-hydroxybutyric acid, inflammation, AMPK signalling, NF-KB signalling

Posted Date: February 18th, 2021

DOI: https://doi.org/10.21203/rs.3.rs-202029/v1

License: (9) (i) This work is licensed under a Creative Commons Attribution 4.0 International License.

Read Full License 


\section{Abstract}

The occurrence of bovine ketosis involves the accumulation of $\beta$-hydroxybutyric acid (BHBA), which contributes to the initiation and acceleration of hepatic metabolic stress and inflammation. Metformin has other beneficial effects apart from its medical intervention for diabetes. This study aims to uncover the role of metformin in modulating BHBA-induced inflammatory responses through the activation of AMPK signalling. Bovine hepatocytes isolated from cows at around 160 days in milk (DIM) were used in this study. Moreover, primary bovine hepatocytes were used for the treatment with BHBA and pretreatment of metformin at different doses. The results demonstrated that BHBA at $1.2 \mathrm{mM}$ triggered the activation of NF-KB signalling and pro-inflammatory cytokines expression. Along with the upregulation of phosphorylated AMPKa and ACCa, metformin at 1.5 and $3 \mathrm{mM}$ inactivated NF-KB signalling components (p65 and IKBa) and the inflammatory genes (TNFA, IL6, IL $1 B$ and COX-2) which were activated by BHBA. Additionally, the pretreatment with metformin increased the BHBA-inhibited cells proliferation. The activation of AMPK resulted in the increased gene and protein expression of SIRT1, along with the deacetylation of H3K9 and H3K14. However, the AMPK inhibitor compound C blocked this effect. Compared to BHBA treated cells, the expression of COX-2 and IL-1 $\beta$ were decreased by the pretreatment with metformin, and the inhibitory effect of metformin was released by compound $C$. The NF-KB displayed higher binding activity onto IL $1 B$ promoter, and this was suppressed by pretreatment with metformin. Altogether, metformin attenuates the BHBA-induced inflammation through the inactivation of NF-KB as a target for AMPK/SIRT1 signalling in bovine hepatocytes.

\section{Introduction}

Elevated $\beta$-hydroxybutyric acid (BHBA) in blood circulation is regarded as one of the leading indicators of bovine ketosis [29]. Unlike monogastric animals, ruminants suffer from physiological stress, pregnancy, and early lactation are exposed to the incidence of negative energy balance (NEB). The NEB caused by the decreased dry matter intake and increased demand for energy to support milk production is often suggested to induce the mobilisation of non-esterified fatty acids (NEFA) and BHBA [20,27]. As one of the main types of ketone bodies, BHBA is overproduced from the partial oxidation of NEFA by hepatic cells [24]. However, the restricted capacity of BHBA utilisation in the liver leads to the excessive accumulation of ketone bodies, which ultimately trigger ketosis. As a result, the occurrence of bovine ketosis is related to the inflammatory response, oxidative stress and metabolic disorders [10]. It has been reported that the plasma concentration of BHBA over $1.2 \mathrm{mM}$ is defined as subclinical ketosis, while those higher than 1.8 $\mathrm{mM}$ are considered as clinical ketosis[16]. Furthermore, previous studies have highlighted that ketosis and infectious disease are positively correlated $[25,26]$.

The inflammatory response is characterised by the coordinated activation of anti- and pro-inflammatory cytokines or chemokines that are rapidly released during tissue injury or infection. Among the various types of signalling that regulates inflammation, the NF-KB complex of transcription factors acts as a master switch in regulating a wealth of immune genes, including pro-inflammatory cytokines like tumour necrosis factor-alpha (TNF-a), interleukin-1 (IL-1), and - 6 (IL-6) [12]. Existing literature suggests that 
BHBA induces the secretion of pro-inflammatory factors through the activation of nuclear factor kappa B (NF-KB) signalling pathway in calf hepatocytes [25]. Moreover, as a ubiquitous and inducible cell transcription factor, NF-KB has been proposed to regulate the production of cyclooxygenase 2 (COX-2) via translocation into the cell nucleus $[35,1,6]$. It has also been reported that COX-2 promoter contains two motif enhancers for NF-KB[23]. Notably, COX-2 is an inducible enzyme that has a role in the immune function, inflammation, apoptosis and angiogenesis[22, 8].

Metformin (1, 1-dimethylbiguanide hydrochloride) was originally developed from natural compounds found in the plant Galega officinalis, known as French lilac or goat's rue. For decades, it has been the firstline therapy for the treatment of type 2 diabetes. An increasing number of studies has suggested that metformin-induced activation of AMPK blocks the inflammatory response via the inhibition of NF-KB signalling pathway in rat aortic smooth muscle cells (RAOSMC) or human umbilical vein endothelial cells (HUVECs) $[30,11]$. Our recent research also revealed that the supply of metformin assists in reducing inflammation via AMPK/NF-KB signalling in LPS-challenged bovine mammary epithelial cells.

Furthermore, studies have demonstrated that AMPK signalling regulates bovine hepatic lipid metabolism in BHBA-mediated disorders [7]. However, the role of AMPK signalling in the regulation of BHBA-induced inflammation of bovine hepatocytes remains unclear.

Recent research has shown that sirtuin 1 (SIRT1) mediates the effect of AMPK-dependent regulation on inflammation and apoptosis in bovine retinal capillary endothelial cells (BREC) and the retina of diabetic rats [41]. Since the activity of SIRT1 is NAD-dependent, innate immunity and energy metabolism are connected through the crosstalk between NF-KB and SIRT1 signalling pathways [19]. Furthermore, the activation of AMPK prevents fatty acid-induced inflammation through SIRT1 in macrophage [38]. Collectively, these studies reveal that the signalling crosstalk among the AMPK, NF-KB and SIRT1 pathways controls the homeostasis of inflammatory phases and energy metabolic supply. This study's hypothesis aims to uncover metformin's suppressive effect on BHBA-induced inflammation through the AMPK/SIRT1/NF-KB signalling pathway in bovine hepatocytes.

\section{Materials And Methods}

\section{Chemicals}

BHBA was purchased from Sigma-Aldrich (St. Louis, MO). The 10-mM BHBA stock solution was prepared in distilled water and sterilised by filtration. Metformin was purchased from Sigma (D150959, SigmaAldrich, St. Louis, US) with a purity of more than $97 \%$. Then, $1 \mathrm{mM}$ of metformin was dissolved in PBS as a stock solution. Compound C (an AMPK inhibitor) was purchased from MedChemExpress ${ }^{\mathrm{TM}}$ (BML-275, $\mathrm{MCE}, \mathrm{NJ}$ ), and $10 \mathrm{mM}$ was prepared in DMSO.

\section{Cell culture conditions}

The bovine hepatocytes used in this study were obtained and cultured in conditions described in the previous publication [32]. The hepatocytes were briefly isolated from the liver tissue of mid-lactation 
multiparous Holstein cows ( $160 \mathrm{~d}$ postpartum). All experiments were performed with cells at the 4 to 6 passage. Cells $\left(2 \times 10^{5}\right)$ were seeded in 6-well plates with overnight incubation in complete medium ( $90 \%$ RPMI 1640, 8119417 Gibco, CA, 10\% fetal bovine serum) (Gibco, CA) and antibiotics (penicillin $100 \mathrm{IU} / \mathrm{ml}$; streptomycin $100 \mu \mathrm{g} / \mathrm{ml}$ ). Finally, the cells were maintained at $37^{\circ} \mathrm{C}$ in a humidified $5 \% \mathrm{CO}_{2}$ incubator until reaching confluence.

\section{Experimental design}

The scale of the BHBA concentration in this study was based on the blood concentration of dairy cows with ketosis. For the pre-experimental treatment, the bovine primary hepatocytes were precultured with serum-free medium for $12 \mathrm{~h}$. For the dose-dependent experiment, cells were treated with metformin for 12 $\mathrm{h}$ at concentrations of $0 \mathrm{mM}, 0.5 \mathrm{mM}, 1.5 \mathrm{mM}, 3 \mathrm{mM}, 5 \mathrm{mM}$, and $10 \mathrm{mM}$. PBS was added to the cells as control group. Cells were treated with BHBA at concentration of $1.2 \mathrm{mM}$ for $12 \mathrm{~h}$ as BHBA group. The hepatocytes were pre-treated with metformin at concentrations of $1.5 \mathrm{mM}$ and $3 \mathrm{mM}$ for $12 \mathrm{~h}$ before the BHBA treatment. The inhibitor of AMPK, Compound C, at a concentration of $10 \mu \mathrm{M}$, was applied to substantiate the AMPK-dependent responses.

\section{Flow cytometry}

Bovine hepatocytes were seeded into 6-well plates $\left(2 \times 10^{5}\right.$ cells/well). Cells were maintained in medium with $10 \%(\mathrm{v} / \mathrm{v})$ fetal bovine serum and the various treatments selected for this study. Cells were treated with metformin at concentrations of $0 \mathrm{mM}, 1 \mathrm{mM}, 2 \mathrm{mM}, 3 \mathrm{mM}, 5 \mathrm{mM}$, and $10 \mathrm{mM}$. The apoptotic effect of metformin on differentiating hepatocytes was evaluated using an Annexin $\mathrm{V}$ staining kit (\#11858777001, Sigma-Aldrich). Cells were collected via trypsinisation and stained. The flow cytometry was analysed using the FACSCalibur platform (BD Biosciences, Franklin Lakes, NJ).

\section{5-ethynyl-2'-deoxyuridine (EdU) detection}

Following the manufacturer's protocols, the BeyoClick ${ }^{\mathrm{TM}}$ EdU cell proliferation kit with Alexa Fluor 555 (Beyotime, Shanghai, China) was used to measure the ability of bovine hepatocytes to proliferate under different treatments. Cells were incubated with $1 \mathrm{X}$ Edu $(10 \mu \mathrm{M})$ solution for $2 \mathrm{~h}$, subsequently fixed with $4 \%$ paraformaldehyde for $20 \mathrm{~min}$ at room temperature (RT), and permeabilised with $0.3 \%$ Triton X-100 in PBS for $15 \mathrm{~min}$ at RT. For nuclear staining, cells were incubated with $1 \mathrm{X}$ Hoechst for $10 \mathrm{~min}$ at RT protected from light. Finally, cells were imaged with a fluorescence microscope DMi8 Microsystems $\mathrm{GmbH}$ (Leica, Wetzlar, Germany) at 200x magnification.

\section{RNA extraction and Real-time quantitative PCR analysis}

Total RNA was isolated with the RNA Isolater Total RNA Extraction Reagent (R401-01, Vazyme, Nanjing, China) according to the manufacturer's instructions. Then, cDNA was synthesised using HiScript III RT SuperMix (R323-01, Vazyme, Nanjing, China) and then purified with a purification kit (Axygen, Tewksbury, MA). In line with a previous study, qRT-PCR was performed using AceQ Universal SYBR qPCR Master Mix 
(Vazyme, Nanjing, China) on an Applied Biosystems QuantStudio 5 Real-Time PCR System (Applied Biosystems, Foster City, CA) [33]. Furthermore, primers were designed with the Premier 6.0 software (Premier Biosoft International, Palo Alto, CA), as illustrated in earlier publications [34, 31]. The selected genes, specifically GAPDH, RPS9, and UXT, were used as internal control genes. The geometric mean of the internal control genes was utilised to normalise the target gene expression data. Previous reports have validated the use of internal control genes as references for normalising gene expression in hepatocytes samples [43]. The $2^{-\Delta \Delta \mathrm{Ct}}$ method was adopted for relative quantification [28].

\section{$\mathrm{NAD}^{+}$measurement}

Using the NAD ${ }^{+} / \mathrm{NADH}$ assay kit with WST-8 according to the manufacturer's instructions (Beyotime, S0175, Beijing, China), after the treatments, hepatocytes $\left(1 \times 10^{6}\right.$ cells/sample) were harvested, and intracellular $\mathrm{NAD}^{+}$levels were determined. Briefly, cell lysis was collected with $200 \mu \mathrm{l}$ of pre-cold lysis buffer. In order to measure the total $\mathrm{NAD}^{+} / \mathrm{NADH}, 20 \mu \mathrm{l}$ of cell lysates was added to a 96 -well plate. Then, measuring NADH required the incubation of the lysed cell suspension at $60^{\circ} \mathrm{C}$ for $30 \mathrm{~min}$, and $20 \mu \mathrm{l}$ was added to a 96 -well plate. Subsequently, $90 \mu \mathrm{l}$ of alcohol dehydrogenase was added and incubated at $37^{\circ} \mathrm{C}$ for $10 \mathrm{~min}$. Finally, $10 \mu \mathrm{l}$ of the chromogenic solution was added to the plate, and the mixture was incubated at $37^{\circ} \mathrm{C}$ for $30 \mathrm{~min}$. The standard curve was generated and measured with the samples simultaneously. The absorbance was obtained at $450 \mathrm{~nm}$ and analysed on a microplate reader (SPARK, TECAN, Switzerland). By subtracting NADH from the total NAD $/ N A D H$, the amount of $N A D^{+}$was derived.

\section{Western-blotting analysis}

Western blot was performed using the protocols described earlier [3]. Equal amounts of protein isolated from pbMEC by RIPA lysis buffer (Beyotime, Shanghai, China) were briefly separated on $10 \%$ SDS polyacrylamide gels (GenScript ExpressPlus ${ }^{\text {TM }}$ PAGE Gels, Nanjing, China). Then, proteins were transferred onto nitrocellulose membranes (Millipore, Billerica, MA), which were incubated with primary antibodies overnight at $4{ }^{\circ} \mathrm{C}$. After washing for 6 consecutive times, the blots were incubated with horseradish peroxidase-coupled secondary antibody. Differences in protein transfer efficiency between blots were normalised with GAPDH quantification. The grey values of the bands of each target protein were quantified using the ImageJ system analysis software. Primary antibodies for p-P65, IL1 $\beta$, TNFa, acetylH3K14, acetyl-H3K9, histone H3, p-AMPKa, AMPKa, p-ACCa, ACCa, COX-2 and SIRT1 were purchased from Cell Signaling Technology (Danvers, MA) (\#3033, \#15101, \#3866, \#7627, \#9649S, \#4499, \#2535, \#5831, \#11818, \#3676, \#12282S, and \# 2496S), and p65 was purchased from Abcam (ab16502) and diluted 1:1,000 for incubation. The primary antibody for GAPDH was purchased from Abcam Corporation (ab8245) and diluted 1:5,000 for incubation.

\section{Immunofluorescence}

After the treatment, bovine hepatocytes $\left(2 \times 10^{4}\right.$ cells/well) were seeded onto 12 -well plates accordingly. Then, the cells were fixed with $4 \%$ paraformaldehyde for $15 \mathrm{~min}$, washed with PBS, and incubated with 
$0.5 \%$ Triton X-100 for 15 min at room temperature to increase the permeability. Incubation with $5 \%$ BSA at $37^{\circ} \mathrm{C}$ for $1 \mathrm{~h}$ was needed for blocking. The cells were incubated at $4{ }^{\circ} \mathrm{C}$ overnight with the primary antibody (targeting the proteins interested) in PBS containing 1\% BSA and 0.3 Triton X-100 (T9284, Sigma-Aldrich). After three PBS washes, the cells were incubated for $1 \mathrm{~h}$ with the secondary antibody in a dark $37^{\circ} \mathrm{C}$ room and then washed three times with PBS. DAPI $(1 \mu \mathrm{g} / \mathrm{mL})(D 8417$, Sigma-Aldrich) was used for nuclear counterstaining for $5 \mathrm{~min}$, and then the cells were washed three times. Finally, the cells were imaged using the DMi8 Microsystems GmbH (Leica, Wetzlar, Germany).

\section{Chromatin immunoprecipitation assay}

The preparation of samples and experiment was performed based on the protocols described previously [31]. The cells were briefly seeded into 6-well plates for treatment and harvested using the PBS containing protease inhibitor cocktail (Cat. \#11697498001; Roche, Basel, Switzerland). Formaldehyde at a concentration of $1 \%$ was added for the cross-link of protein and DNA. After shaking for 10 min, glycine was used to stop the reaction. The mix was then centrifuged at $4{ }^{\circ} \mathrm{C}$ with $4000 \times \mathrm{g}$ for $5 \mathrm{~min}$. Chromatin preparations were fragmented at 200 to $500 \mathrm{bp}$ in length with sonication on ice and then incubated with 4 $\mu \mathrm{g}$ of primary antibody (Anti-P65, ab16502, Abcam) at $4^{\circ} \mathrm{C}$ for $16 \mathrm{~h}$. Rabbit IgG was incubated with the sample as a negative control. Protein A/G agarose beads ( $40 \mu \mathrm{L}, 50 \%$ slurry, sc-2003; Santa Cruz Biotechnology) were utilised to capture immunoprecipitated chromatin complexes, and $200 \mu \mathrm{L}$ of chromatin preparation served as the input. Promoter fragments harvested during chromatin immunoprecipitation were quantified with qPCR using primers specific to the respective areas of $I L 1 B$ promoter (forward 5' GGCT CAGCTTGTAAAGAATC 3' and reverse 5' GAATGCACGAAAGTC ATCC 3').

\section{Statistics}

The data were expressed as the means \pm standard deviation (mean \pm SD) and analysed using one-way ANOVA with Dunnett's post-test by SAS Statistics (v 9.2, SAS Institute Inc., Cary, NC). Differences with Pvalues $<0.05$ were considered statistically significant. All experiments were carried out in triplicate, with three replicates in each experiment.

\section{Results}

\section{Determination of metformin's cytotoxic effect under different doses}

Metformin's cytotoxicity was determined using flow cytometry and results were shown in the Figure 1. At doses ranging from 0 to $3 \mathrm{mM}$, no cytotoxic effect of metformin was observed. Significant cytotoxicity was found at doses of 5 and $10 \mathrm{mM}$ with increased apoptotic cells compared to that in the control cells. Based on the cytotoxic study of metformin, we selected the specific doses of 1.5 and $3 \mathrm{mM}$ for use in the following experiments.

\section{Determination of BHBA-induced inflammatory responses and AMPK activation by metformin}


To verify the BHBA-induced inflammatory responses, we examined the protein expression in terms of the phosphorylation levels of $\mathrm{p} 65, \mathrm{COX}-2$ and IL-1 $\beta$ with an increasing amount of BHBA in bovine hepatocytes. The significant upregulation of phosphorylated p65 appeared at the BHBA concentrations of 1.2, 2.4 and $10 \mathrm{mM}$ compared with the $0 \mathrm{mM}$ BHBA group $(P<0.05)$. Consistently, BHBA at doses of 1.2 and 2.4 induced a dramatic increase in staining and translocation of p65 into nuclear. COX-2 concentration exhibited elevation in the cells treated with 1.2 and $2.4 \mathrm{mM}$ of BHBA compared to the $0 \mathrm{mM}$ group $(P<0.5)$. Additionally, the level of IL-1 $\beta$ protein expressed proximately was two folds higher in 1.2 mM BHBA treated cells than that of the cells in the 0 mM BHBA group $(P<0.05)$. Interestingly, BHBA at a concentration of $20 \mathrm{mM}$ decreased the IL-1 $\beta$ expression, though the cells treated with 2.4 and $10 \mathrm{mM}$ of BHBA displayed upregulation of IL-1 $\beta$ compared with the 0 mM BHBA group $(P<0.05)$. Figures $2 A, 2 B$ and $2 \mathrm{E}$ illustrate the data.

In order to confirm the role of metformin in activating AMPK signalling in bovine hepatocytes, we incorporated the test for phosphorylation of AMPKa and ACCa using western blots, as shown in Figures $2 \mathrm{C}$ and 2D. After increasing the amount of metformin added to the cells, the phosphorylation of AMPKa was upregulated at doses ranging from 1.5 to $10 \mathrm{mM}$ compared to the $0 \mathrm{mM}$ metformin-treated cells ( $\mathrm{P}<$ 0.05). After adding metformin, the concentration of phosphorylated ACCa increased from $0.5 \mathrm{mM}$ all the way to $10 \mathrm{mM}(\mathrm{P}<0.05)$. Based on the results of metformin's significant cytotoxicity at doses higher than $5 \mathrm{mM}$, both 1.5 and $3 \mathrm{mM}$ were deemed optimal doses for use in the succeeding experiments.

\section{Metformin reversed the BHBA-induced pro-inflammatory genes expression}

Figure $3 \mathrm{~A}$ presents the expression of genes related to inflammatory responses. BHBA induced the increase of pro-inflammatory genes expression at the dose of $1.2 \mathrm{mM}$, as a result of the upregulation of TNFA, IL6, IL 1B and COX-2, compared with the NC group $(\mathrm{P}<0.05)$. In addition to the downregulation of TNFA and $I L 1 B$ by metformin treatment, the expressions of the BHBA-induced upregulated inflammatory genes (TNFA, IL6, IL1B and COX-2) were also suppressed by the pretreatment with metformin following BHBA induction $(P<0.05)$. Moreover, as an anti-inflammatory gene, the relative $I L 10$ gene level of the cells pretreated with metformin at $3 \mathrm{mM}$ following BHBA treatment was significantly upregulated compared to the BHBA-primed cells $(P<0.05)$.

\section{Metformin affected the BHBA-induced activation of NF-KB signalling pathway and inhibition of cells proliferation}

As shown in the BHBA-induced activation of NF-KB signalling, metformin is effective in the suppression of BHBA-activated NF-KB signalling. Figures 3B, $3 \mathrm{C}$ and $3 \mathrm{D}$ illustrate the data. Compared with the NC group, the addition of BHBA upregulated the protein expression of phosphorylated IKBa and NF-KB subunit p65 $(P<0.05)$. However, significant inactivation of NF-KB signalling with regards to the decreased level of phosphorylated $\mathrm{lkBa}$ and $\mathrm{p} 65$ was observed in the cells pretreated with metformin compared to the BHBA group $(P<0.05)$. We further studied metformin's effect on BHBA-induced NF-KB translocation (Figure 3D). In addition to the strongly stained p65, the translocation of p65 into nuclear was also 
observed in BHBA-treated cells. However, cells pretreated with metformin inhibited this BHBA-induced NFKB nuclear translocation.

As a result of the inhibited and stained EdU, a BHBA dose of $1.2 \mathrm{mM}$ affected the cells proliferation, compared with the control group. However, cells pretreated with metformin at a concentration of $3 \mathrm{mM}$ blocked the effect of BHBA-mediated suppression of cells proliferation (Figure 3E).

\section{SIRT1 is involved in the AMPK-mediated regulation of histone deacetylation}

The levels of phosphorylated AMPKa and ACCa were lower in BHBA-primed bovine hepatocytes than those in the NC group. Cells pretreated with metformin significantly upregulated the activity of AMPK signalling with regards to the increased expression of phosphorylated AMPKa and ACCa. The AMPK inhibitor compound $\mathrm{C}$ blocked the effect of metformin on the AMPK signalling pathway activation, resulting in the equal levels of AMPKa and ACCa phosphorylation with the NC group.

Afterwards, we examined the expressions of SIRT1 and acetylated histone $\mathrm{H} 3$ at the positions of K9 and $\mathrm{K} 14$. The decreased gene and protein expression of SIRT1 induced by BHBA was upregulated by pretreatment with metformin $(P<0.05)$. Compound $C$ significantly blocked metformin's effect on the regulation of SIRT1 activity $(P<0.05)$. As changes in SIRT1, a histone deacetylase, the histone H3 deacetylation was also altered in both BHBA addition and metformin treatment. BHBA induced a dramatic hyperacetylation with regards to the H3K9 and H3K14 compared to the control cells $(P<0.05)$. However, this increasing acetylation was suppressed by the pretreatment with metformin at both $\mathrm{H} 3 \mathrm{~K} 9$ and H3K14. It is worth noting that the treatment of cells with the AMPK inhibitor compound $\mathrm{C}$ led to the interruption of $\mathrm{H} 3 \mathrm{~K} 14$ deacetylation that resulted from metformin pretreatment, but not to the level of H3K9 acetylation. Figures 4C, 4D and 4E present the data.

Since AMPK mediates the activity of $\mathrm{NAD}^{+}$-dependent histone deacetylase SIRT1, we investigated the concentration of $\mathrm{NAD}^{+} / \mathrm{NADH}$ in hepatocytes subjected to BHBA and metformin treatment. According to the results, BHBA led to the reduction of $\mathrm{NAD}^{+}$and elevation of $\mathrm{NADH}$ compared to the control cells $(\mathrm{P}<$ 0.05). However, the pretreatment of metformin significantly reversed the alteration of BHBA-affected production of $\mathrm{NAD}^{+}$and NADH. Moreover, the BHBA-induced decrease in the ratio of NAD+/NADH was increased by the pretreatment with metformin $(P<0.05)$. Figure 4 presents the data.

\section{Inhibitory effect of metformin on inflammatory responses is driven by AMPK signalling}

To further demonstrate the anti-inflammatory effect of metformin through an AMPK-dependent way, we tested the blockade of AMPK, which may result in the abrogation of metformin regulating immune responses in bovine hepatocytes. As shown in Figures 5A and 5B, the increased protein expression of COX- 2 and IL-1 $\beta$ induced by BHBA were dampened by the pretreatment with metformin. Compound $\mathrm{C}$ blocked metformin's preventive effect on the regulation of COX-2 and IL-1 $\beta$ protein expression. 
Since the acetylation of histone $\mathrm{H} 3$ may contribute to the difficulties associated with chromatin accessibility for DNA transcription initiation and subsequent protein expression, we incorporated the test for the NF-KB binding ability onto the IL $1 B$ promoter. The putative binding site for NF-KB on $I L 1 B$ promoter was analysed using the online PROMO software (http://alggen.Isi.upc.es/cgibin/promo_v3/promo/promoinit.cgi?dirDB=TF_ 8.3). Filters $\geq 0.90$ was established as the threshold for the similarity of the core sequence. The result showed that BHBA could drive the binding activity of NF-KB onto the IL1B promoter. In contrast, pretreatment with metformin interdicted the binding ability of NF-KB compared to that in the BHBA treated cells $(P<0.05)$, which is consistent with the decreased translocation of p65 into nuclear (Figures $5 \mathrm{C}$ and $5 \mathrm{D}$ ).

\section{Discussion}

As one of the primary ketones, BHBA is overproduced during the excessive NEB-induced lipid mobilisation from the adipose tissue. The occurrence of bovine ketosis accompanied with BHBA elevation induces metabolic stress in the liver. Consequently, higher BHBA levels in the serum lead to metabolic disorders, reproductive failure and inflammatory responses in lactating cows. In this study, we found that BHBA at a concentration of $1.2 \mathrm{mM}$ results in the inflammation of primary bovine hepatocytes. However, cells pretreated with metformin attenuate the BHBA-induced inflammation through the regulation of AMPK/SIRT1/NF-KB signalling pathway.

The NF-kB transcription factor significantly contributes to the central regulation of mammalians inflammatory process. Lipopolysaccharide (LPS), a well-known stimulator for NF-kB signalling, induces systemic inflammation in hepatocytes and the liver of dairy cows, as previously reported in vivo and in vitro. It is worth noting that BHBA has been proposed to elicit the increase of pro-inflammatory factors TNF- $\alpha$, IL- 6 and IL- $1 \beta$ through the activation of NF-KB signalling in calf hepatocytes. Hence, the activation of NF-KB contributes to hepatic inflammation induced by both pathogenic infections and metabolic stress. Consistently, we found that increasing the BHBA amount led to the upregulation of phosphorylated NF-kB subunit p65. Along with the increase of the translocation of NF-kB into nuclear, the increased secretion of COX-2 and IL-1 $\beta$ indicates that BHBA functions to stimulate the hepatic stress with an overaccumulation of ketone and drive the cells into an inflammatory response.

Although studies have reported numerous concerns regarding metformin's role in the regulation of inflammation, the underlying mechanism of the anti-inflammatory effects is still not fully understood. Some have revealed that AMPKa contributes to the crucial mechanisms underlying metformin's pleiotropic effects on different types of tissues [17, 15, 37, 39]. Nevertheless, existing literature suggests that metformin mediates the anti-inflammatory effects through both AMPKa dependent and independent way in human retinal microvascular endothelial cells [18]. In this study, metformin at a concentration of $1.5 \mathrm{mM}$ appeared to activate AMPK signalling by increasing the levels of phosphorylated AMPKa and phosphorylated ACCa. However, the inhibitor of AMPKa (Compound C) blocked the metformin-induced activation of AMPKa in bovine hepatocytes. These results confirmed that AMPK signalling activation is 
involved in the effect of metformin and brought insights into the AMPK-dependent way of metformin in bovine hepatocytes.

Studies have put forward that AMPK could dampen inflammatory responses by modulating NF-KB, MAPK and JAK/STAT signalling pathways. In this study, we investigated metformin's inhibitory effect on the BHBA-induced inflammation response in bovine hepatocytes. Interestingly, cells pretreated with metformin lowered the BHBA-induced expression of pro-inflammatory genes (IL 1B, TNFA, IL6, COX-2) and the expression of proteins (IL-1 $\beta$ and COX-2). Reports have highlighted that AMPK is required for the IL-10 activation of the mTORC1- and STAT3-mediated anti-inflammatory pathways regulating macrophage functional polarisation in mice [44]. Moreover, our study found that AMPK contributes to the antiinflammatory effect with regards to the activation of IL10 expression. Concurrently, our results demonstrated that metformin decreased the BHBA-induced expression of phosphorylation of p65 and the translocation of p65 in bovine hepatocytes along with the blocked phosphorylation of IKBa. Since NF-KB could be activated and acts as a master switch in regulating the expression of genes concerned with the inflammation in nuclear, our outcomes indicated that metformin might conduct the modulation of immune genes through NF-KB inactivation. Although metformin was suggested to reduce cells proliferation, like its role in anti-cancer properties, no effect was found in normal cells, such as the HEK293/TLR4 cells in a recent study [21, 2, 42]. This supports that metformin may affect cells with a high proliferative and metabolic rate like tumour cells, but not the normal tissue cells. Similar to what was observed in cells proliferation, our results demonstrated that pretreatment with metformin enhanced the hepatocytes proliferation that was dampened by BHBA. Collectively, these outcomes imply that the inhibition of NF-KB by activation of AMPK is pivotal for metformin's anti-inflammatory action. Although its underlying mechanism has not been completely uncovered, the reduction of inflammatory responses by AMPK and SIRT1 activation might be involved [36].

To determine by which way AMPK activation could attenuate NF-KB activity induced by BHBA in bovine hepatocytes, we investigated SIRT1-regulated histone deacetylation. Emerging pieces of evidence have suggested that SIRT1 mimics AMPK's numerous effects on energy sensing and metabolism [5]. Additionally, with the elevation of $\mathrm{NAD}+\mathrm{NADH}$, the activation of SIRT1 represents both NF-KB deacetylation and histone deacetylation $[19,9]$. Several mechanisms take place through the inhibitory effect of SIRT1 on specific target gene by modulating the chromatin structure, such as histone modification, acetylation of transcription factors, or DNA methylation [40]. The reversed histone deacetylation at both $\mathrm{K} 9$ and $\mathrm{K} 14$ in the pretreatment of metformin following BHBA-induction in this study indicates that activation of SIRT1 may contribute to the inhibitory expression of immune genes through histone deacetylation. Furthermore, AMPK inhibitor compound $\mathrm{C}$ blocks the metformin-induced activation of SIRT1, and deacetylation of histone at lysine 14 may also evidence the role of AMPK/SIRT1 in the downregulation of pro-inflammatory genes induced by BHBA.

COX-2 is the main enzyme that responds to inflammation through the synthesis of prostaglandins in monocytes and macrophages [13]. However, COX-2 is also expressed in many cell types like noninflammatory cells (fibroblasts, epithelial and endothelial cells) $[4,14]$. Along with the decrease of 
phosphorylated p65 in cells pretreated with metformin, we found that Compound $\mathrm{C}$ also reduces the effects of AMPK-mediated suppression of COX-2 and IL-1 $\beta$ protein expression. Moreover, the decreased binding ability of NF-KB p65 onto the IL-1B promoter in cells pretreated with metformin followed by BHBA stimulation also substantiates the lower levels of $I L 1 B$ gene expression. However, further studies are required to verify the direct regulation of metformin on the modulation of proteins, such as protein deacetylation by SIRT1 activation.

Altogether, these results indicate that BHBA induces inflammatory responses through the activation of NF-KB signalling, while pretreatment with metformin dampens the pro-inflammatory cytokines through the activation of AMPK. The regulation of histone deacetylation by SIRT1 may illustrate the mechanism of the downregulated cytokines expression. Therefore, AMPK/SIRT1/NF-KB signalling may point to the new mechanism of bovine hepatocytes inflammatory response and a potential target for the development of a ketosis therapy.

\section{Declarations}

\section{Ethics approval and consent to participate}

All experimental procedures were approved by the Animal Experiment Committee of Yangzhou University, in accordance with the Regulations for the Administration of Affairs Concerning Experimental Animals (The State Science and Technology Commission of China, 1988) published by the Ministry of Science and Technology, China, in 2004. All of the experimental protocols were performed in accordance with the approved guidelines and regulations.

\section{Availability of data and material}

The datasets used and/or analyzed during the current study are available from the corresponding author on reasonable request.

\section{Consent for publication}

Not applicable

\section{Conflicts of interests}

The authors declare no conflicts of interests

\section{Funding}

This study was supported by the National Natural Science Foundation of China (31872324).

\section{Authors' contributions}


$\mathrm{Xu} T$, and Lu $\mathrm{X}$ analyzed and interpreted the data. Arbab A performed the experiment, and $\mathrm{Xu} T$ and Yang $Z$ were major contributor in writing the manuscript. Yang $Z$ support to the financial cost throughout the experiment and generate the ideas. All authors read and approved the final manuscript.

\section{References}

1. Ackerman, W. E. th, T. L. Summerfield, D. D. Vandre, J. M. Robinson, and D. A. Kniss. 2008. Nuclear factor-kappa $B$ regulates inducible prostaglandin $E$ synthase expression in human amnion mesenchymal cells. Biol Reprod 78 (1):68-76. doi:10.1095/biolreprod.107.061663.

2. Brodowska, Katarzyna, Sofia Theodoropoulou, Meyer Zu H???Rste Melissa, Eleftherios Paschalis, Kimio Takeuchi, Gordon Scott, David Ramsey, Elizabeth Kiernan, Mien Hoang, and Joanna Cichy. 2014. Effects of metformin on retinoblastoma growth in vitro and in vivo. International Journal of Oncology 45 (6).

3. Chen, Zhi, Shuangfeng Chu, Xiaolong Wang, Yujia Sun, Tianle Xu, Yongjiang Mao, Juan J. Loor, and Zhangping Yang. 2019. MiR-16a Regulates Milk Fat Metabolism by Targeting Large Tumor Suppressor Kinase 1 (LATS1) in Bovine Mammary Epithelial Cells. Journal of Agricultural and Food Chemistry 67 (40):11167-11178. doi:10.1021/acs.jafc.9b04883.

4. Dannenberg, A. J., N. K. Altorki, J. O. Boyle, C. Dang, L. R. Howe, B. B. Weksler, and K. Subbaramaiah. 2001. Cyclo-oxygenase 2: a pharmacological target for the prevention of cancer. Lancet Oncol 2 (9):544-551. doi:10.1016/s1470-2045(01)00488-0.

5. Dasgupta, B., and J. Milbrandt. 2007. Resveratrol stimulates AMP kinase activity in neurons. Proc Natl Acad Sci U S A 104 (17):7217-7222. doi:10.1073/pnas.0610068104.

6. Deng, J., S. A. Miller, H. Y. Wang, W. Xia, Y. Wen, B. P. Zhou, Y. Li, S. Y. Lin, and M. C. Hung. 2002. betacatenin interacts with and inhibits NF-kappa B in human colon and breast cancer. Cancer Cel/ 2 (4):323-334. doi:10.1016/s1535-6108(02)00154-x.

7. Deng, Q., G. Liu, L. Liu, Y. Zhang, L. Yin, X. Shi, J. Wang et al. . 2015. BHBA influences bovine hepatic lipid metabolism via AMPK signaling pathway. J Cell Biochem 116 (6):1070-1079. doi:10.1002/jcb.25062.

8. Fosslien, E. 2000. Molecular pathology of cyclooxygenase-2 in neoplasia. Ann Clin Lab Sci 30 (1):321.

9. Gillum, M. P., M. E. Kotas, D. M. Erion, R. Kursawe, P. Chatterjee, K. T. Nead, E. S. Muise et al. . 2011. SirT1 regulates adipose tissue inflammation. Diabetes 60 (12):3235-3245. doi:10.2337/db11-0616.

10. Hammon, D. S., I. M. Evjen, T. R. Dhiman, J. P. Goff, and J. L. Walters. 2006. Neutrophil function and energy status in Holstein cows with uterine health disorders. Vet Immunol Immunopathol 113 (12):21-29. doi:10.1016/j.vetimm.2006.03.022.

11. Hattori, Y., K. Suzuki, S. Hattori, and K. Kasai. 2006. Metformin inhibits cytokine-induced nuclear factor kappaB activation via AMP-activated protein kinase activation in vascular endothelial cells. Hypertension 47 (6):1183-1188. doi:10.1161/01.Hyp.0000221429.94591.72. 
12. Hayden, M. S., and S. Ghosh. 2011. NF-KB in immunobiology. Cell Res 21 (2):223-244. doi:10.1038/cr.2011.13.

13. Hinson, R. M., J. A. Williams, and E. Shacter. 1996. Elevated interleukin 6 is induced by prostaglandin E2 in a murine model of inflammation: possible role of cyclooxygenase-2. Proc Natl Acad Sci U S A 93 (10):4885-4890. doi:10.1073/pnas.93.10.4885.

14. Howe, L. R., and A. J. Dannenberg. 2002. A role for cyclooxygenase-2 inhibitors in the prevention and treatment of cancer. Semin Oncol 29 (3 Suppl 11):111-119. doi:10.1053/sonc.2002.34063.

15. Huang, Nan Lan, Shu Hui Chiang, Chia Hsiang Hsueh, Yao Jen Liang, Yi Jung Chen, and Ling Ping Lai. 2009. Metformin inhibits TNF-a-induced IKB kinase phosphorylation, IKB-a degradation and IL-6 production in endothelial cells through PI3K-dependent AMPK phosphorylation. 134 (2):0-175.

16. Iwersen, M., D. Klein-Jöbstl, M. Pichler, L. Roland, B. Fidlschuster, I. Schwendenwein, and M. Drillich. 2013. Comparison of 2 electronic cowside tests to detect subclinical ketosis in dairy cows and the influence of the temperature and type of blood sample on the test results. J Dairy Sci 96 (12):77197730. doi:10.3168/jds.2013-7121.

17. Jian, M. Y., M. F. Alexeyev, P. E. Wolkowicz, J. W. Zmijewski, and J. R. Creighton. 2013. Metforminstimulated AMPK-a1 promotes microvascular repair in acute lung injury. Am J Physiol Lung Cell Mol Physiol 305 (11):L844-L855.

18. Jing, Han, Li Yue, Liu Xiuli, Zhou Tongrong, Sun Haijing, Edwards Paul, Gao Hua, Yu Fu-Shin, Qiao Xiaoxi, and Chen Jing. 2018. Metformin suppresses retinal angiogenesis and inflammation in vitro and in vivo. PLoS One 13 (3):e0193031.

19. Kauppinen, A., T. Suuronen, J. Ojala, K. Kaarniranta, and A. Salminen. 2013. Antagonistic crosstalk between NF-KB and SIRT1 in the regulation of inflammation and metabolic disorders. Cell Signal 25 (10):1939-1948. doi:10.1016/j.cellsig.2013.06.007.

20. McArt, J. A., D. V. Nydam, G. R. Oetzel, T. R. Overton, and P. A. Ospina. 2013. Elevated non-esterified fatty acids and $\beta$-hydroxybutyrate and their association with transition dairy cow performance. Vet $J$ 198 (3):560-570. doi:10.1016/j.tvjl.2013.08.011.

21. Queiroz, E. A., S Puukila, R Eichler, S. C. Sampaio, H. L. Forsyth, S. J. Lees, A. M. Barbosa, R. F. Dekker, Z. B. Fortes, and N Khaper. Metformin Induces Apoptosis and Cell Cycle Arrest Mediated by Oxidative Stress, AMPK and FOX03a in MCF-7 Breast Cancer Cells. PLoS One.

22. Seibert, K., and J. L. Masferrer. 1994. Role of inducible cyclooxygenase (COX-2) in inflammation. Receptor 4 (1):17-23.

23. Shi, G., D. Li, J. Fu, Y. Sun, Y. Li, R. Qu, X. Jin, and D. Li. 2015. Upregulation of cyclooxygenase-2 is associated with activation of the alternative nuclear factor kappa B signaling pathway in colonic adenocarcinoma. Am J Transl Res 7 (9):1612-1620.

24. Shi, X., X. Li, D. Li, Y. Li, Y. Song, Q. Deng, J. Wang et al. . 2014. $\beta$-Hydroxybutyrate activates the NF-kB signaling pathway to promote the expression of pro-inflammatory factors in calf hepatocytes. Cell Physiol Biochem 33 (4):920-932. doi:10.1159/000358664. 
25. Shi, Xiaoxia, Xinwei Li, Dangdang Li, Yu Li, Yuxiang Song, Qinghua Deng, Jianguo Wang, Yuhang Zhang, Hongyan Ding, and Liheng Yin. 2014. $\beta$-Hydroxybutyrate Activates the NF-kB Signaling Pathway to Promote the Expression of Pro-Inflammatory Factors in Calf Hepatocytes. Cellular Physiology \& Biochemistry International Journal of Experimental Cellular Physiology Biochemistry \& Pharmacology 33 (4):920.

26. Song, Y., N. Li, J. Gu, S. Fu, Z. Peng, C. Zhao, Y. Zhang et al. . 2016. $\beta$-Hydroxybutyrate induces bovine hepatocyte apoptosis via an ROS-p38 signaling pathway. J Dairy Sci 99 (11):9184-9198. doi:10.3168/jds.2016-11219.

27. Song, Y., X. Li, Y. Li, N. Li, X. Shi, H. Ding, Y. Zhang, X. Li, G. Liu, and Z. Wang. 2014. Non-esterified fatty acids activate the ROS-p38-p53/Nrf2 signaling pathway to induce bovine hepatocyte apoptosis in vitro. Apoptosis 19 (6):984-997. doi:10.1007/s10495-014-0982-3.

28. W, Pfaffl Michael. 2001. A new mathematical model for relative quantification in real-time RT-PCR. Nuclc Acids Research (9):9.

29. Xia, C., Z. Wang, C. Xu, and H. Y. Zhang. 2012. Concentrations of plasma metabolites, hormones, and mRNA abundance of adipose leptin and hormone-sensitive lipase in ketotic and nonketotic dairy cows. J Vet Intern Med 26 (2):415-417. doi:10.1111/j.1939-1676.2011.00863.x.

30. Xiaorui, Cao, Li Huan, Tao Huiren, Wu Ning, Yu Lifeng, Zhang Dawei, Lu Xiaozhao, Zhu Jinyu, Lu Zifan, and Zhu Qingsheng. 2013. Metformin Inhibits Vascular Calcification in Female Rat Aortic Smooth Muscle Cells via the AMPK-eNOS-NO Pathway. Endocrinology (10):3680-3689.

31. Xu, T. L., H. M. Seyfert, and X. Z. Shen. 2017. Epigenetic mechanisms contribute to decrease stearoylCoA desaturase 1 expression in the liver of dairy cows after prolonged feeding of high-concentrate diet. Journal of Dairy Science.S0022030217311670.

32. Xu, Tianle, Nana Ma, Yan Wang, Xiaoli Shi, Guangjun Chang, Juan J. Loor, and Xiangzhen Shen. 2018. Sodium Butyrate Supplementation Alleviates the Adaptive Response to Inflammation and Modulates Fatty Acid Metabolism in Lipopolysaccharide-Stimulated Bovine Hepatocytes. Journal of Agricultural and Food Chemistry 66 (25):6281-6290. doi:10.1021/acs.jafc.8b01439.

33. Xu, Tianle, Nana Ma, Wang Yan, Xiaoli Shi, Guangjun Chang, Juan J. Loor, and Xiangzhen Shen. 2018. Sodium butyrate supplementation alleviates the adaptive response to inflammation and modulates fatty acid metabolism in lipopolysaccharide-stimulated bovine hepatocytes. Journal of Agricultural \& Food Chemistry.acs.jafc.8b01439-.

34. Xu, Tianle, Hui Tao, Guangjun Chang, Kai Zhang, Lei Xu, and Xiangzhen Shen. 2015. Lipopolysaccharide derived from the rumen down-regulates stearoyl-CoA desaturase 1 expression and alters fatty acid composition in the liver of dairy cows fed a high-concentrate diet. BMC Vet Res 11:52-52. doi:10.1186/s12917-015-0360-6.

35. Yamamoto, K., T. Arakawa, N. Ueda, and S. Yamamoto. 1995. Transcriptional roles of nuclear factor kappa B and nuclear factor-interleukin- 6 in the tumor necrosis factor alpha-dependent induction of cyclooxygenase-2 in MC3T3-E1 cells. J Biol Chem 270 (52):31315-31320.

doi:10.1074/jbc.270.52.31315.

Page $14 / 21$ 
36. Yang, H., Y. Bi, L. Xue, J. Wang, Y. Lu, Z. Zhang, X. Chen et al. . 2015. Multifaceted Modulation of SIRT1 in Cancer and Inflammation. Crit Rev Oncog 20 (1-2):49-64.

doi:10.1615/critrevoncog.2014012374.

37. Yang, Sheng, Xiaohe Chen, Yuanyuan Xu, Yan Hao, and Xianfang Meng. 2020. Effects of metformin on lipopolysaccharide-induced depressive-like behavior in mice and its mechanisms. Neuroreport 31 (4):305-310.

38. Yang, Z., B. B. Kahn, H. Shi, and B. Z. Xue. 2010. Macrophage alpha1 AMP-activated protein kinase (alpha1AMPK) antagonizes fatty acid-induced inflammation through SIRT1. J Biol Chem 285 (25):19051-19059. doi:10.1074/jbc.M110.123620.

39. Ye, Jinhui, Zhu, Na, Sun, Ruipu, Liao, Wangdi, Fan, and Shipan. 2018. Metformin Inhibits Chemokine Expression Through the AMPK/NF-kappa B Signaling Pathway. Journal of Interferon \& Cytokine Research the Official Journal of the International Society for Interferon \& Cytokine Research.

40. Zhang, Tong, and W. Lee Kraus. 2010. SIRT1-dependent regulation of chromatin and transcription: Linking NAD+ metabolism and signaling to the control of cellular functions. Biochimica et Biophysica Acta (BBA) - Proteins and Proteomics 1804 (8):1666-1675.

doi:https://doi.org/10.1016/j.bbapap.2009.10.022.

41. Zheng, Z., H. Chen, J. Li, T. Li, B. Zheng, Y. Zheng, H. Jin, Y. He, Q. Gu, and X. Xu. 2012. Sirtuin 1mediated cellular metabolic memory of high glucose via the LKB1/AMPK/ROS pathway and therapeutic effects of metformin. Diabetes 61 (1):217-228. doi:10.2337/db11-0416.

42. Zhihui, Xiao, Wu Wenjun, and Poltoratsky Vladimir. 2017. Metformin Suppressed CXCL8 Expression and Cell Migration in HEK293/TLR4 Cell Line. Mediators Inflamm 2017:1-11.

43. Zhou, Y., Z. Zhou, J. Peng, and J. J. Loor. 2018. Methionine and valine activate the mammalian target of rapamycin complex 1 pathway through heterodimeric amino acid taste receptor (TAS1R1/TAS1R3) and intracellular Ca(2+) in bovine mammary epithelial cells. J Dairy Sci 101 (12):11354-11363. doi:10.3168/jds.2018-14461.

44. Zhu, Yanfang Peipei, Jonathan R Brown, Duygu Sag, Lihua Zhang, and Jill Suttles. 2015. Adenosine 5'-monophosphate-activated protein kinase regulates IL-10-mediated anti-inflammatory signaling pathways in macrophages. Journal of Immunology 194 (2):584.

\section{Figures}




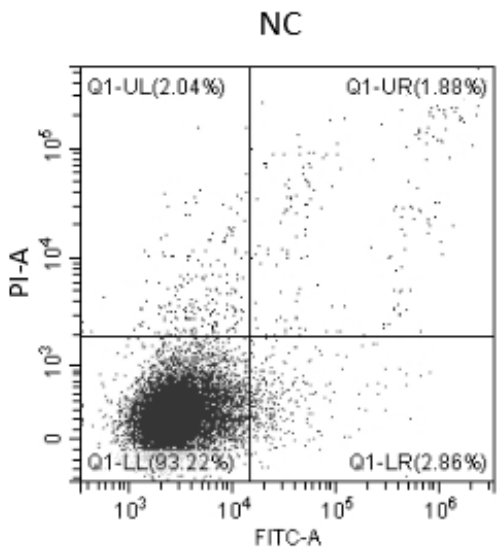

Met, $3 \mathrm{mM}$

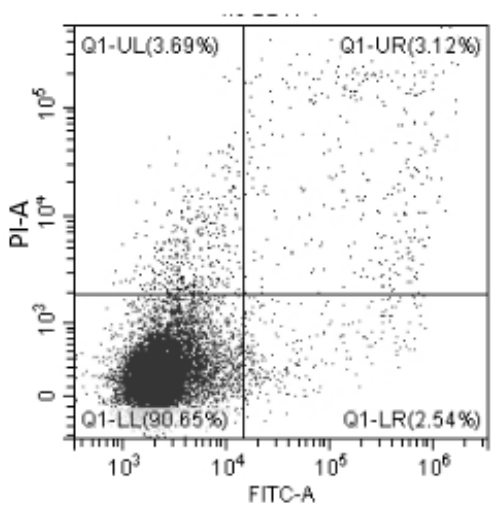

Met, $0.5 \mathrm{mM}$

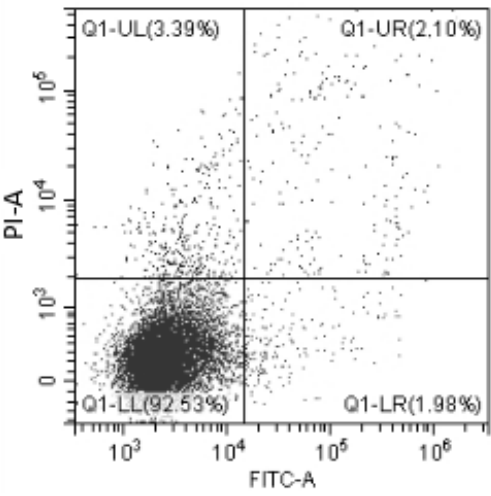

Met, $5 \mathrm{mM}$

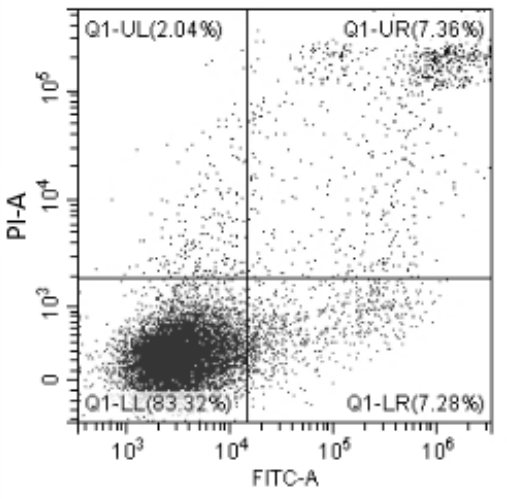

Met, $1.5 \mathrm{mM}$

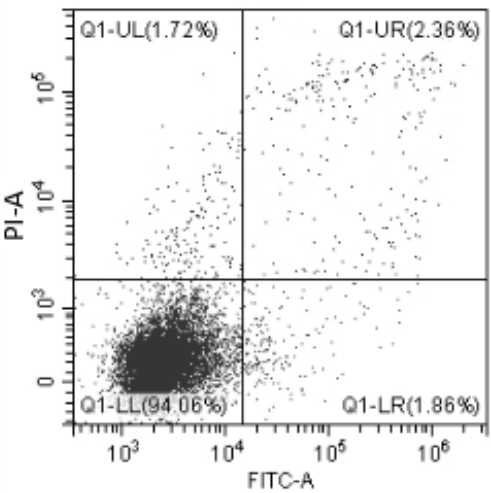

Met, $10 \mathrm{mM}$

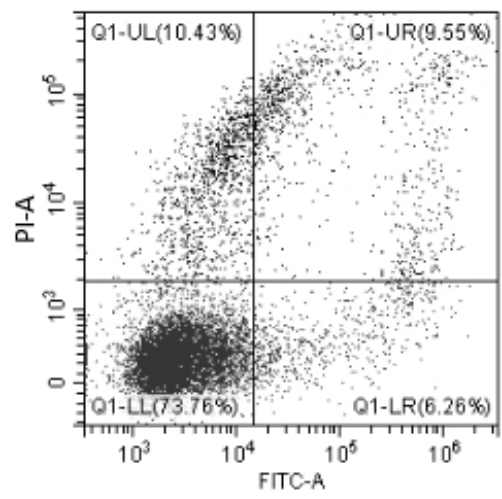

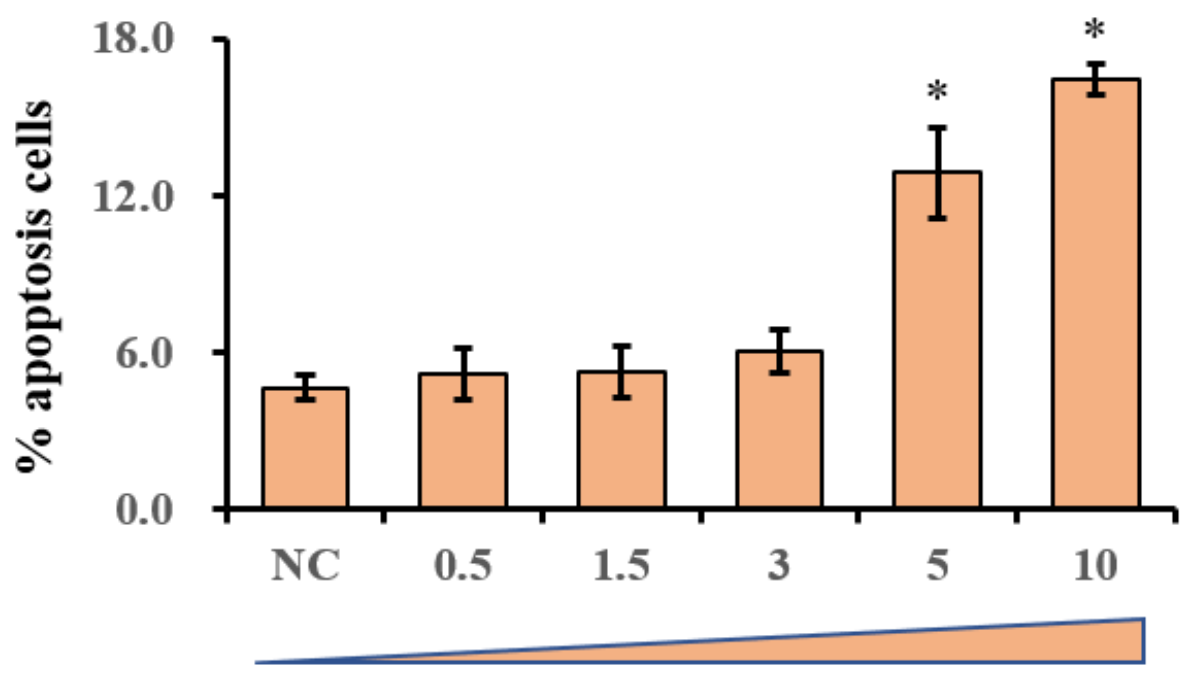

Metf. Concentrition (mM)

\section{Figure 1}

Flow cytometric analysis of hepatocytes treated with different doses of metformin. Results were expressed as the mean $\pm S D$. (A) Absorbance of FITC-A; absorbance of fluorescein isothiocyanate-Annexin $\mathrm{V}$. (B) The apoptosis percentages in cultures exposed to different doses of metformin. ${ }^{*} P<0.05$ vs the NC group. These data are representative of three independent experiments. 
A

BHBA (mM) 00.61 .22 .41020

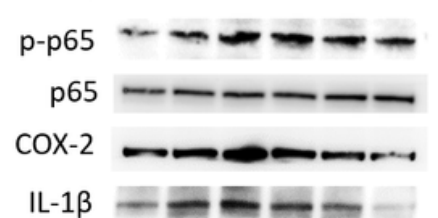

GAPDH - - - -

C

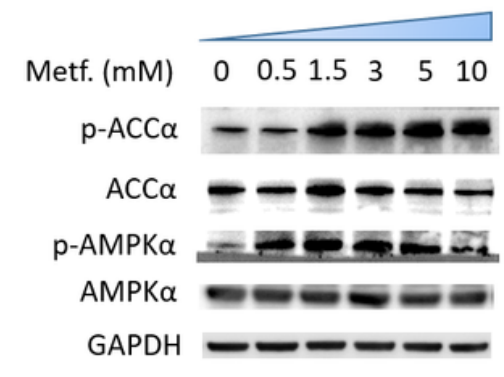

B

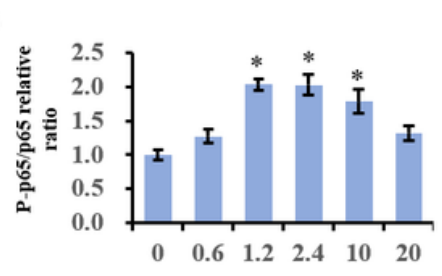

D
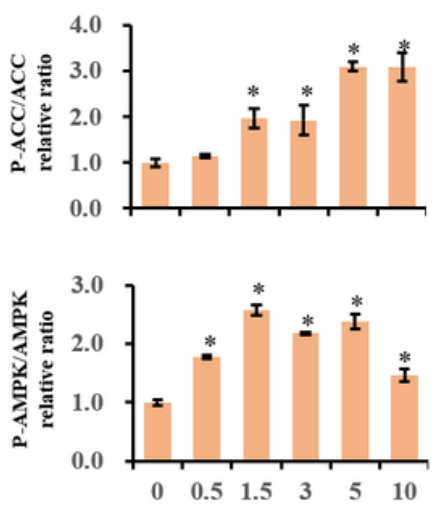

Metf. Concentrition (mM)
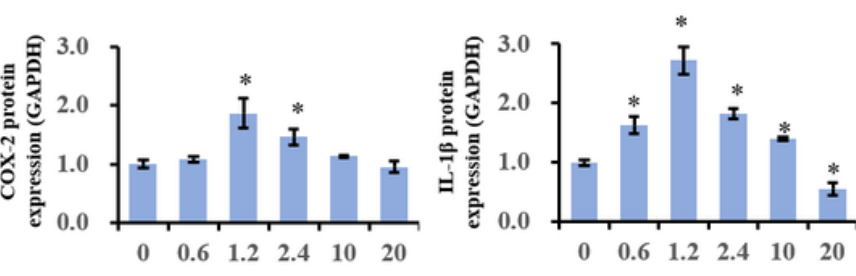

BHBA Concentrition (mM)

E

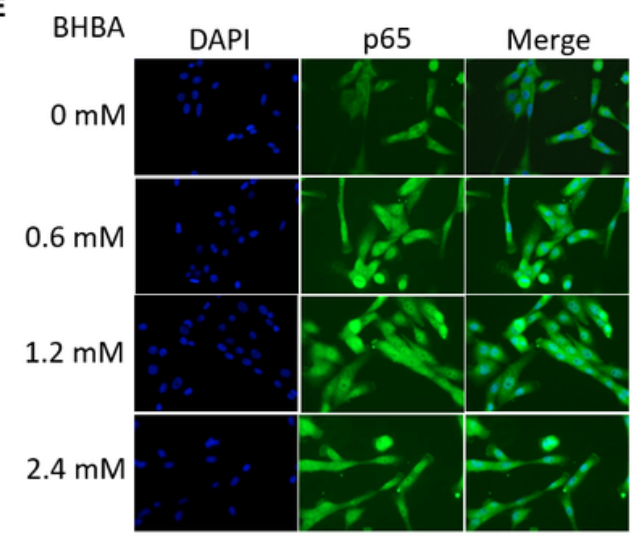

\section{Figure 2}

Determination of BHBA induced inflammatory responses and AMPK activation by metformin. Results were expressed as the mean $\pm S D$. $(A, B)$ Immunoblotting and intensity from the respective blots. *P $<$ 0.05 vs the cell without treatment with $\operatorname{BHBA}(0 \mathrm{mM})$. (C, D) Immunoblotting and intensity from the respective blots. ${ }^{*} \mathrm{P}<0.05$ vs the cell without treatment with metformin $(0 \mathrm{mM})$. The proteins expression were normalized by the respective abundance of GAPDH. (E) Effect of BHBA on the location of NF-kB p65 protein in bovine hepatocytes with different doses. Cells were treated with $\operatorname{BHBA}(0,0.6,1.2,2.4 \mathrm{mM})$ for 6 h. Immunofluorescence for NF-KB p65 (green) was performed, and the nuclear dye DAPI (blue) was used. 
A

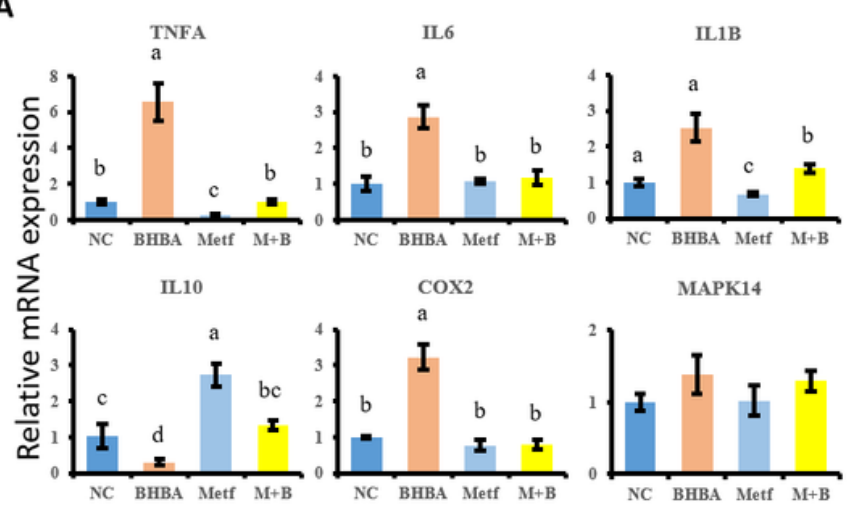

B

$\begin{array}{lllll}\mathrm{BHBA}(\mathrm{mM}) & 0 & 1.2 & 1.2 & 1.2\end{array}$ Metf. (mM) $\quad 0 \quad 0 \quad 1.5 \quad 3$

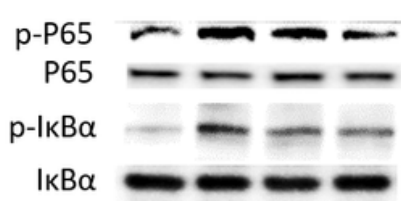

C

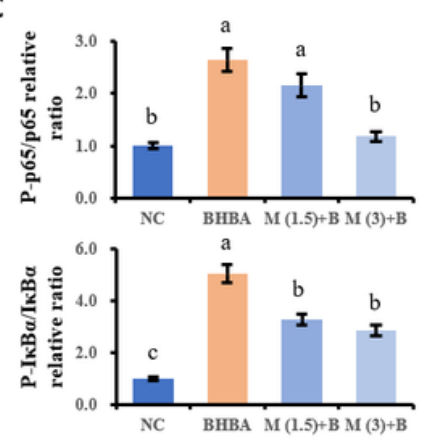

D
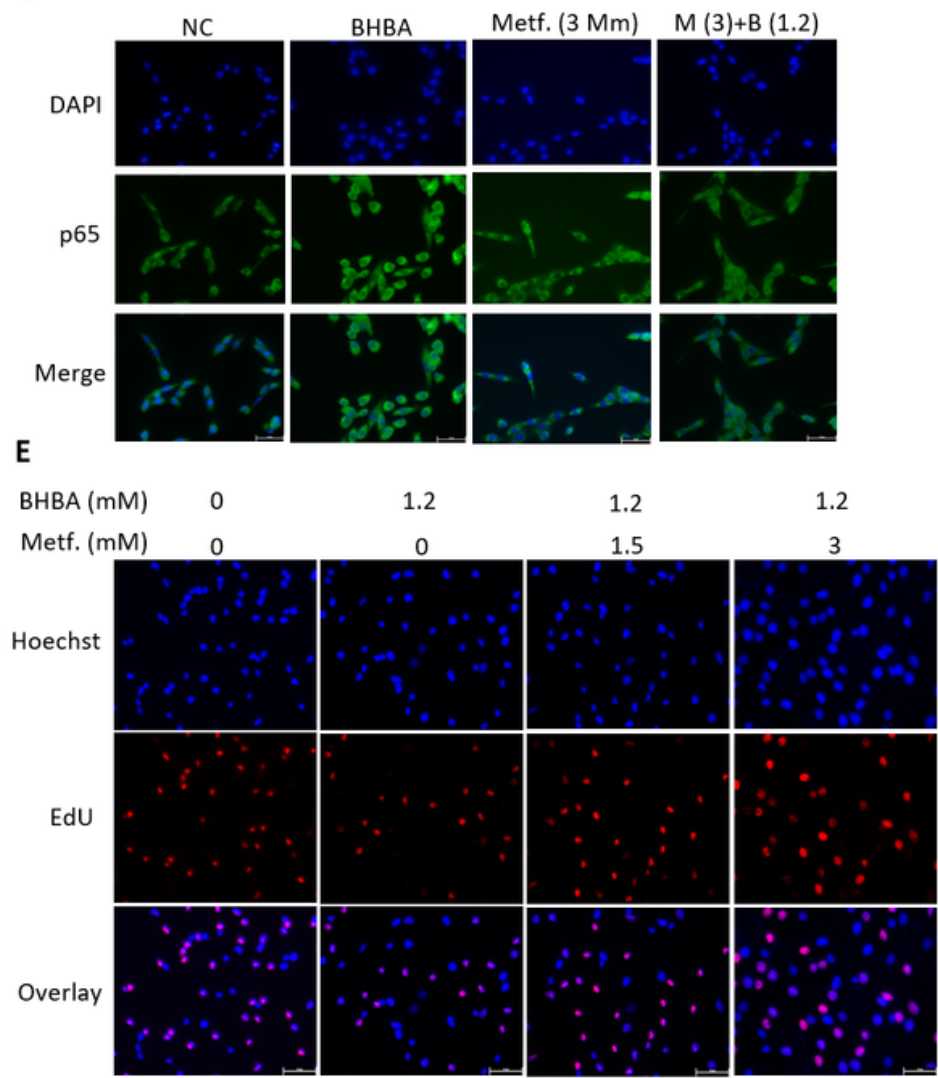

\section{Figure 3}

The suppressive effect of metformin on the BHBA induced pro-inflammatory responses. (A) The expression of genes associated with pro- and anti-inflammation, normalized by the geometric mean of the internal control genes (GAPDH, UXT and RPS9). (B, C) Protein levels of phosphorylated p65 and IKBa in each group of bovine hepatocytes. The letters in superscript indicate that the difference between groups was significant $(P<0.05)$. (D) Immunofluorescence for detecting p65 activity. After fixation and permealization steps, cells were stained with antibody against subunit p65 of NF-kB and counterstained with DAPI for nuclear staining. (E) EdU assay for cell proliferation. Cells were pretreated with or without metformin at doses of 1.5 and $3 \mathrm{mM}$ for $12 \mathrm{~h}$, followed by the induction of $1.2 \mathrm{mM} \mathrm{BHBA}$ for $6 \mathrm{~h}$. Results were expressed as the mean \pm SD. 
A

$\begin{array}{llllllll}\mathrm{BHBA}(\mathrm{mM}) & 0 & 1.2 & 1.2 & 1.2 & 0 & 1.2\end{array}$

Metf. (mM) $\quad \begin{array}{lllllll}0 & 0 & 1.5 & 3 & 0 & 3\end{array}$

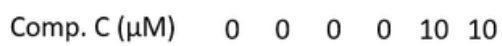

$\mathrm{p}-\mathrm{AMPK \alpha}=\mathbf{- 0}=$

AMPK $\alpha$

$\mathrm{p}-\mathrm{ACC} \alpha$

$\mathrm{ACC} \alpha=-\cdots$

GAPDH

C

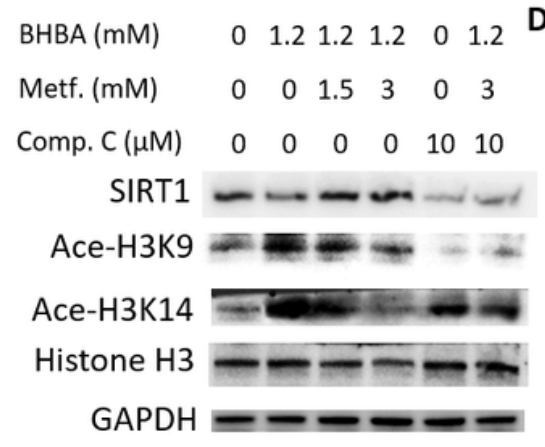

B
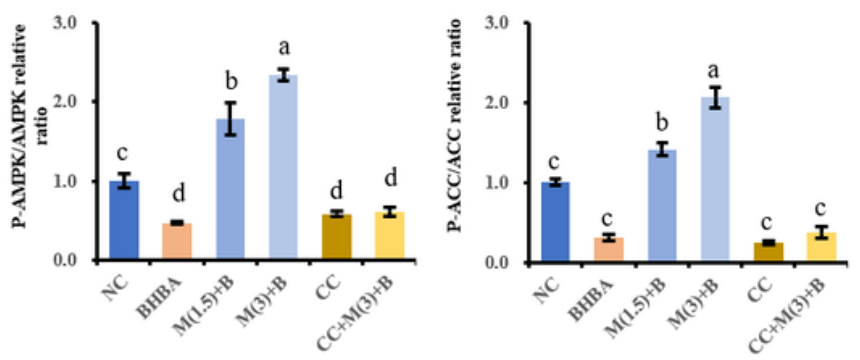

E

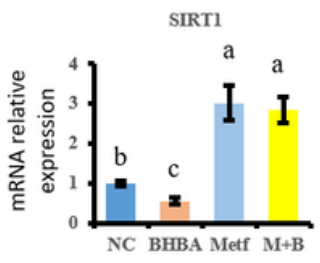

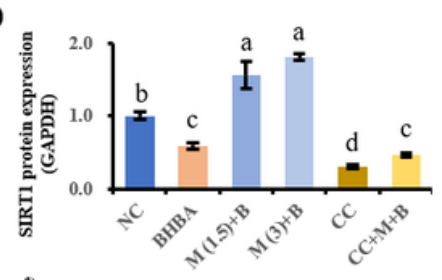
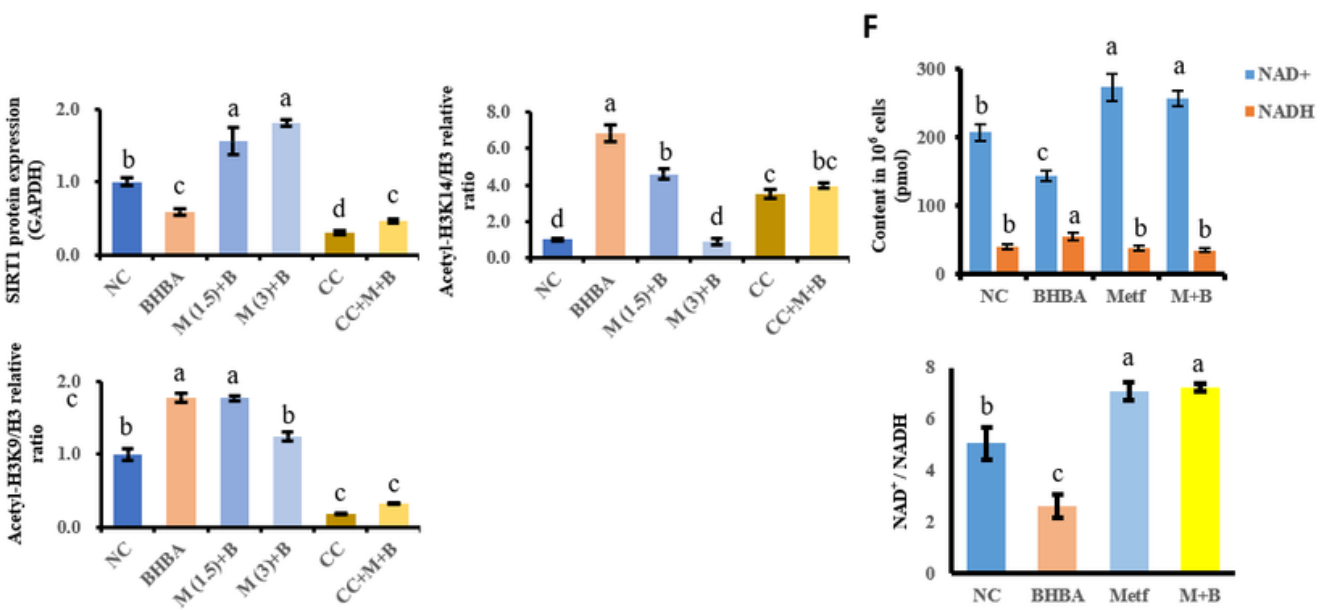

Figure 4

The involvement of AMPK signaling in regulating SIRT1 expression and Histone H3 deacetylation. (A, B) Immunoblotting and intensity from the respective blots. (C, D) Immunoblotting and intensity from the respective blots. Compound $\mathrm{C}$ were represented for the inhibitory effect of AMPK activity. The proteins expression were normalized by the respective abundance of GAPDH. (E) mRNA expression of SIRT1 normalized with geometric mean of GAPDH, UXT and RPS9. (F) The concentration of NAD+/NADH using WST-8 assay. Cells were pretreated with or without metformin at doses of 1.5 and $3 \mathrm{mM}$ for $12 \mathrm{~h}$, followed by the induction of $1.2 \mathrm{mM} \mathrm{BHBA}$ for $6 \mathrm{~h}$. The letters in superscript indicate that the difference between groups was significant $(P<0.05)$. Results were expressed as the mean $\pm \mathrm{SD}$. These data are representative of three independent experiments. 
A

$\begin{array}{llllllll}\mathrm{BHBA} & (\mathrm{mM}) & 0 & 1.2 & 1.2 & 1.2 & 0 & 1.2\end{array}$

Metf. (mM) $\quad 0 \quad 0 \quad 1.5 \quad 3 \quad 003$

Comp. $\mathrm{C}(\mu \mathrm{M}) \quad 0 \quad 0 \quad 0 \quad 0 \quad 10 \quad 10$

COX-2
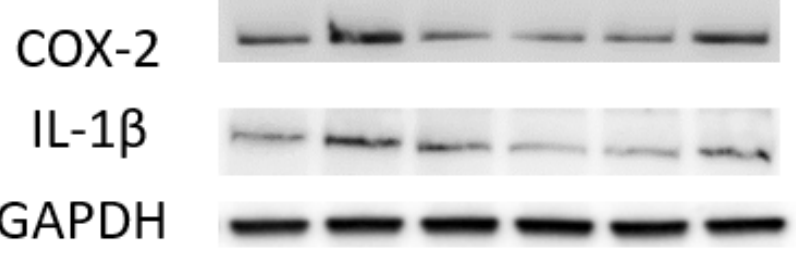

B
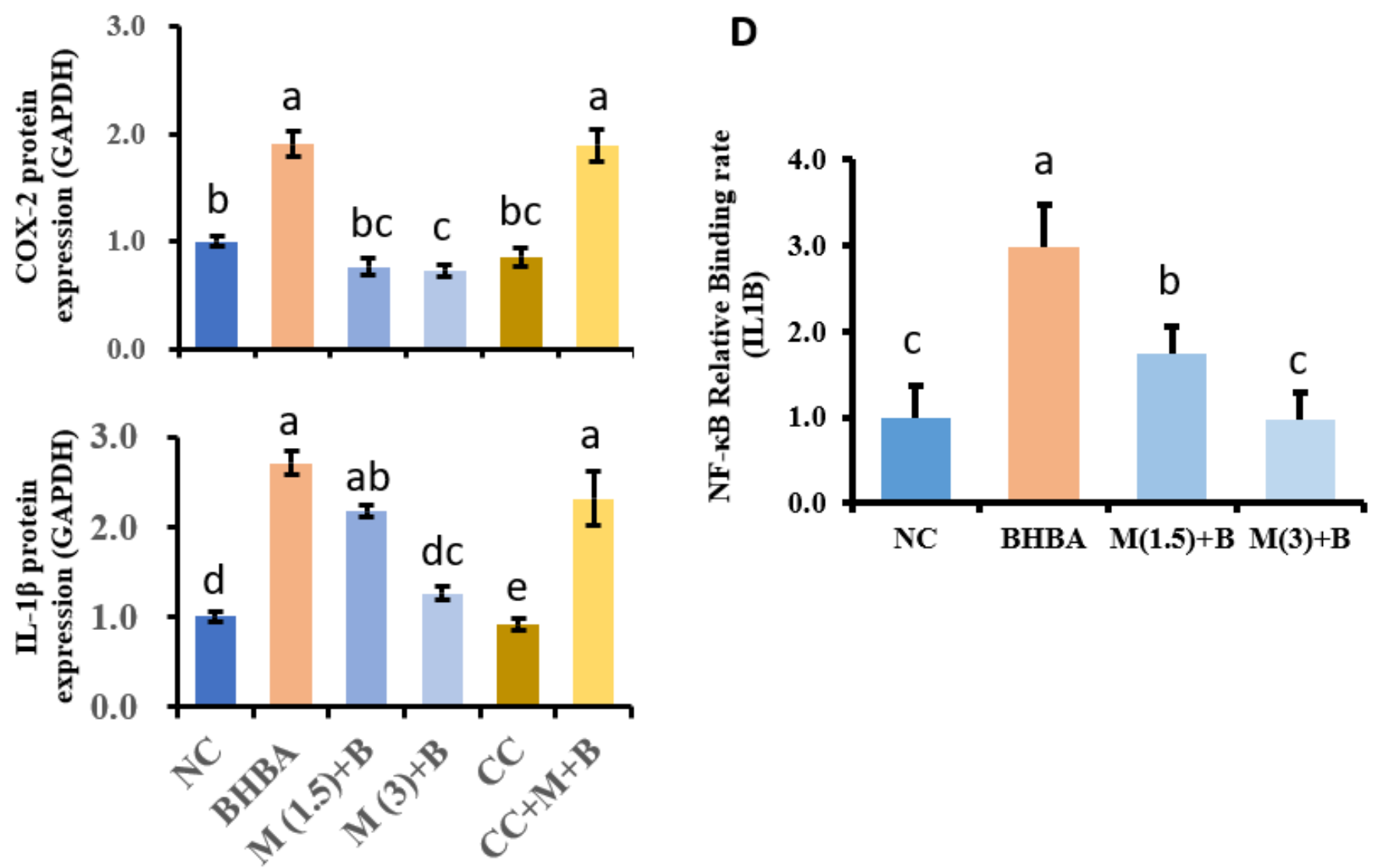

Figure 5

AMPK is required for the metformin mediated inhibition of pro-inflammatory proteins expression. (A, B) Immunoblotting and intensity from the respective blots. Compound $\mathrm{C}$ were represented for the inhibitory effect of AMPK activity. The proteins expression were normalized by the respective abundance of GAPDH. (C) Numbers refer to the position relative to the transcriptional starting site, indicated by black arrows. The position of the transcription factors is indicated by the respective symbols. The positions of primers used for chromatin immunoprecipitation assays are denoted by dark lines surround the symbol of NF-KB. The identification for target promoter regions of candidate genes were determined by BLAST analyses as DNA-sequences that are $5^{\prime}$-upstream of the mRNA sequences deposited in the NCBI: NM_174093.1 (IL1B). (D) Level of NF-KB binding to IL1B promoter. Six individual samples in each group 
were involved in generating chromatin immunoprecipitation analysis. The letters in superscript indicate that the difference between groups was significant $(P<0.05)$. Cells were pretreated with or without metformin at doses of 1.5 and $3 \mathrm{mM}$ for $12 \mathrm{~h}$, followed by the induction of $1.2 \mathrm{mM} \mathrm{BHBA}$ for $6 \mathrm{~h}$. Results were expressed as the mean \pm SD. These data are representative of three independent experiments. 